\title{
Pedofilia. Un punto de vista endocrinológico
}

\section{Pedophilia seen by endocrinologists}

$\mathrm{S}_{\mathrm{r}}^{\mathrm{r}}$ Editor: La sociedad chilena se ha conmocioado por el abuso de menores, incluyendo la pedofilia, una realidad que Chile se negaba a aceptaryt. En la discusión del tema se advierte una ausencia de participación médica, tanto en los medios de comunicación como en el trámite parlamentario de la ley sobre pedofilia 0 ante el proyecto que propuso la castración para los pedofílicos.

El DSM IV (Diagnostic and Statistical Manual of Mental Disorders) ${ }^{2}$ define la parafilia como un impulso recurrente, urgente a excitarse con fantasías o acciones que involucran: 1. Objetos no humanos; 2. Sufrir o inferir humillación o daño a uno mismo o a su pareja sexual; 3. Dirigirse a niños o a personas que no consienten esta conducta. Debe existir a lo menos por 6 meses, en forma permanente 0 episódica y se sitúa claramente fuera de las prácticas sexuales socialmente aceptadas, llamadas antiguamente perversiones sexuales, hoy parafilias. La parafilia, palabra formada por el prefijo para (al lado de o anormal) y philia (amor), ocasiona riesgos y sufrimientos a quien la realiza y daña severamente al otro afectado, especialmente cuando es un niño.

La mayoría de las parafilias ocurren en hombres, con excepción del masoquismo, existiendo varios tipos: exhibicionismo, voyeurismo, fetichismo, travestismo, sadismo, masoquismo, pedofilia, etc. $^{2-4}$.

La pedofilia es una parafilia en que hay una atracción sexual intensa, urgente, recurrente, por los niños, existiendo casi exclusivamente apetito sexual y excitación incontrolables por los menores de 13 años ${ }^{2}$.

El pedofílico utiliza la seducción, violencia (incluyendo violación y riesgo de muerte), remunerar al menor para conseguir aceptación, induciendo incluso a la drogadicción y alcoholismo.
Su curso puede ser permanente, manteniendo contactos con una o varias víctimas, o presentar períodos de abstinencia con episodios pedofílicos.

Etiología: Se han invocado predisposiciones psicopatológicas, ya que existen antecedentes de violencia familiar, abuso sexual en su infancia, abuso de drogas, etc. Los psiquiatras han buscado interpretaciones en modelos psicofisiológicos obsesivos, compulsivos, adictivo ${ }^{5,6}$.

Se ha planteado una alteración neuroendocrina como base del cuadro, ya que en algunos casos se ha vinculado su aparición con daños orgánicos cerebrales que afectan al hipotálamo o al sistema límbico; sin embargo, las mediciones de testosterona no han mostrado diferencias con la población general.

Diagnóstico: La evaluación psicológica busca demostrar esta atracción sexual anormal hacia los niños y la racionalización de esta conducta, justificándola como que el niño deseaba placer sexual, amor, etc.

Considerando que muchos pedofilicos niegan su conducta, se requiere tener un alto grado de sospecha y confiar en la información de los afectados.

Debe descartarse que hayan otros desórdenes psiquiátricos, retardo mental, trastornos orgánicos cerebrales, abuso de drogas, que lleven en forma secundaria a este problema. La pedofilia es generalmente un trastorno primario, que se presenta sin patología previa.

La alteración de la excitación sexual (que sólo ocurre ante el estímulo de un menor), se ha podido confirmar utilizando pletismografía peneana y el registro de la erección («Regiscan»), para constatar su desencadenamiento ante videos que muestran actividades pedofílicas con niños de uno u otro sexo. 
Tratamiento: Psicoterapia orientada a que el pedofílico tome conciencia de su enfermedad, del daño que produce en otros y de sus riesgos personales, familiares, económicos y sociales ${ }^{7}$. Terapia conductual que utiliza métodos aversivos para desplazar la excitación con niños, hacia adultos de cualquier sexo que consientan libremente tener actividad sexual.

El tratamiento orgánico (farmacológico y hormonal) se basa en que la líbido o deseo sexual y la fase de excitación, incluyendo la erección, requieren un nivel normal de testosterona. Esta hormona actuaría en núcleos cerebrales que intervienen en el deseo, y generan la respuesta neuroendocrina y neurovascular de la excitación y erección.

Por esta base biológica de la sexualidad, disminuir o antagonizar la testosterona es de utilidad terapéutica mediante: 1 . Castración: elimina la principal fuente de testosterona, presenta un bajo porcentaje de recidivas, aunque puede ser contrarrestada por la automedicación con andrógeno; 2. Fármacos antidepresivos: aumentando la serotonina disminuyen la líbido y la excitación sexual, son complemento de la terapia psiquiátrica favoreciendo menos recidivas; 3 . Terapia endocrina: disminuyendo la secreción de andrógenos o interfiriendo su acción en el efector (antiandrógenos) inhiben la líbido, excitación y erección. Se han utilizado: a) acetato de medroxiprogesterona, b) análogos del GNRH y c) antiandrógenos (acetato de ciproterona) $)^{8,9}$.

\section{REFERENCIAS}

1. Melús P. Pedofilia: una realidad que Chile se negaba a aceptar. Revista Síndrome Niño Agredido 2003; 58: 6.

2. DSM IV. Diagnostic and statistical manual of mental disorders, 4 ed. American Psychiatric Association, Washington DC 1994; 527-8.

3. Chartton R. Evaluation of sexual disorders. En: Treating sexual disorders. Ed Jossey-Bass Inc., Publishers. San Francisco, California 1997; 59-80.

4. Charlton R. Treatment of paraphilias. En: Treating sexual disorders. Ed Jossey-Bass Inc., Publishers. San Francisco, California 1997; 281-310.

5. KaPLAN HS. Erotic obsession: relationship to hypoactive sexual desire disorders and paraphilia. Am J Psychiatry 1996; 153: 3041.
Ningún tratamiento consigue la curación de la pedofilia. Es necesario realizarlo para disminuir las recaídas y agresiones sexuales. La terapia endocrina es efectiva y menos mutiladora que la castración, sólo si el paciente la mantiene por voluntad propia o coerción legal.

La legislación en distintos países hace recaer sobre la Medicina y el Estado serias responsabilidades, estableciendo la castración de los pedofilicos $\mathrm{u}$ obligándolos a aceptar una terapia psiquiátrica y farmacológica, hospitalizados en unidades de psiquiatría forense de cárceles o en servicios de salud mental. Las leyes establecen que para obtener libertad condicional se requiere el diagnóstico médico de «curación» del pedofílico y no constituir peligro para la sociedad. Considerando la no curación y la frecuencia de recidivas, esta disposición legal hace recaer sobre el médico la responsabilidad de dejarlo permanentemente recluido en dichos servicios, o asumir el riesgo de los actos del pedofílico una vez liberado $0^{10,11}$.

El costo de estas terapias: hospitalización y el contar con equipos multidisciplinarios, implican un gasto importante para el Estado. Todos estos aspectos deberían ser considerados al legislar sobre esta materia.

\section{Dr. Enzo Devoto C, Dra. Lucía Aravena C.}

Sección Endocrinología, Hospital Clínico San BorjaArriarán, Santiago, Chile.

Facultad de Medicina de la Universidad de Chile, Campus Central.

6. Travin S. Compulsive sexual behaviors. Psych Clin North Am 1995; 18: 155-69.

7. FULER AK. Child molestation and pedophilia. JAMA 1989; 261: 602-6.

8. BRADFORD JMW. Organic treatment for the male sexual offender. Ann NY Acad Sci 1988; 528: 193202.

9. RösLer A, WitzTum E. Treatment of men paraphilia with a long acting analogue of gonadrotropin releasing hormone JAMA 1998; 338: 216-422.

10. Stone TH, Winstade WJ, Jlugman CM. Sex offenders, sentencing laws and pharmaceutical treatment: a prescription for failure. Behav Sci Law 2000; 18: 83-100.

11. Brody AL, GreEN R. Washington State's unscientific approach to the problem of repeat sex offenders. Bull Am Acad Psychiatric Law 1994; 22: 343-56. 